\title{
4M method - new application of Mössbauer spectroscopy to classification of meteorites. How it works?
}

\author{
Jolanta Gałązka-Friedman ${ }^{1}$ (ID - Martyna Jakubowska ${ }^{1} \cdot$ Marek Woźniak $^{2}$ (D) . \\ Patrycja Bogusz ${ }^{1} \cdot$ Łukasz Karwowski $^{3} \cdot$ Przemysław Duda $^{1}$
}

Accepted: 8 November 2021 / Published online: 9 December 2021

(c) The Author(s) 2021

\begin{abstract}
4M method is a new application of Mössbauer spectroscopy to quantitative classification of ordinary chondrites. 4M derives from four words: meteorites, Mössbauer spectroscopy, multidimensional discriminant analysis, Mahalanobis distance. This method was published by us in 2019. In this paper we present application of $4 \mathrm{M}$ method to classification of four meteorites. Link to script with calculation needed for classification of ordinary chondrites was given.
\end{abstract}

Keywords Mössbauer spectroscopy - 4M method - Classification of ordinary chondrites · Multidimensional discriminant analysis · Mahalanobis distance · Villalbeto de la Pena meteorite

\section{$14 \mathrm{M}$ method - What it is?}

4M method is a new application of Mössbauer spectroscopy for classification of ordinary chondrites, the most frequent meteorites found on the Earth. They represent about $75 \%$ of all meteoritic falls. As ordinary chondrites were formed 4.56 billion years ago, studying of them may enlarge our knowledge about the origin of Solar System. The 4M method was published by our group in 2019 in a journal concentrated on investigation of meteorites with the use of various methods - Meteoritics and Planetary Science [1]. 4M derives from four words: meteorites, Mössbauer spectroscopy, multidimensional discriminant analysis, Mahalanobis distance. First method of classification of ordinary chondrites was proposed in the half of the XX century. This method was based on the finding of 3 types of ordinary

This article is part of the Topical Collection on Proceedings of the International Conference on the Applications of the Mössbauer Effect (ICAME 2021), 5-10 September 2021, Brasov, Romania Edited by Victor Kuncser

Jolanta Gałązka-Friedman

jolanta.friedman@pw.edu.pl

1 Faculty of Physics, Warsaw University of Technology, Koszykowa 75, 00-662 Warsaw, Poland

2 Faculty of Biology, University of Warsaw, Miecznikowa 1, 02-096 Warsaw, Poland

3 Faculty of Natural Sciences, University of Silesia, Sosnowiec, Poland 


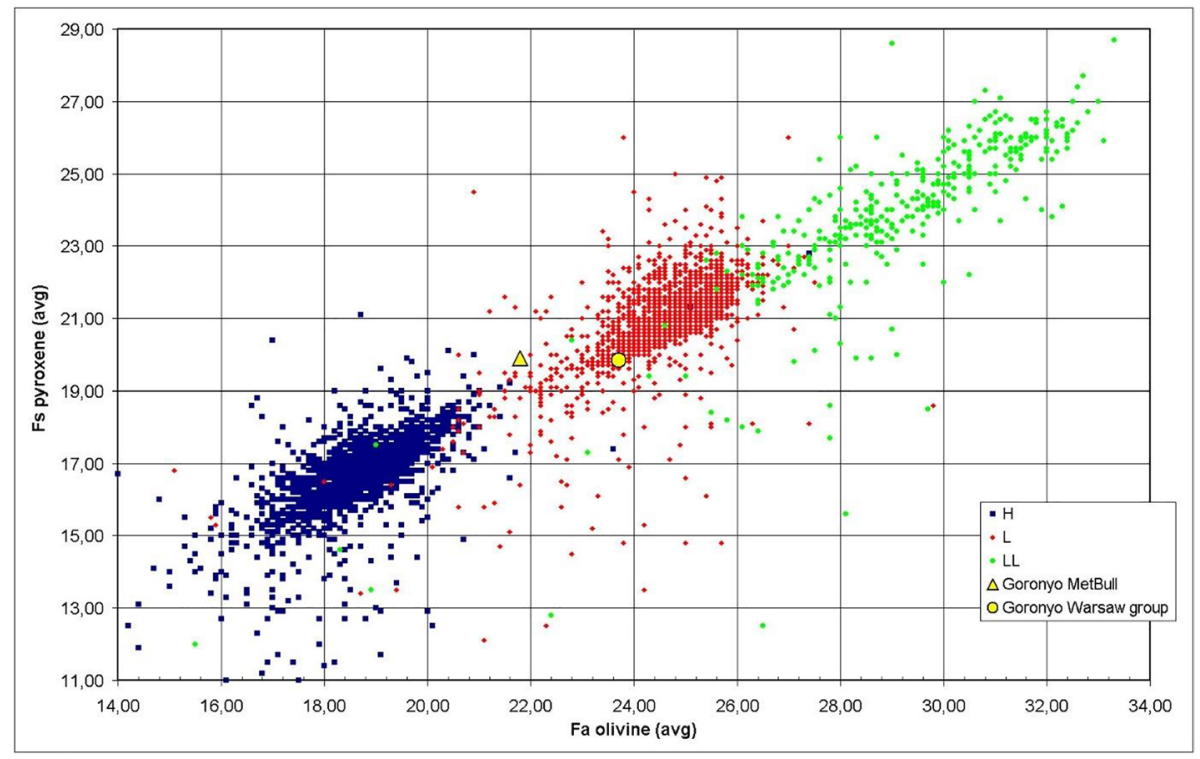

Fig. 1 Amount of ferrosilite (Fs) in orthopyroxenes versus amount of fayalite (Fa) in olivines obtained for 4712 ordinary chondrites - the values are taken from Koblitz 2012 [3]

chondrites containing different amounts of iron - type $\mathrm{H}$ (high amount of iron), type L (low amount of iron) and LL (low amount of iron and metal). The universally used method of classification of ordinary chondrites is based on determination of the ratio of amount of ferrosilite (Fs) in orthopyroxenes versus amount of fayalite (Fa) in olivines. This method was introduced by Fredriksson and Keil in 1964 [2]. The measurements are performed with the use of electron microprobe. They are very time consuming but they do separate these 3 types of meteorites, which is shown in Fig. 1.

The separation of ordinary chondrites of type H, L and LL shown in Fig. 1 is very well seen. On this plot we put also points corresponding to the meteorite Goronyo. Their positions were determined based on data from MetBull (Meteoritical Bulletin Database), according to which it is located on the border between $\mathrm{H}$ and $\mathrm{L}$, while based on the data from Warsaw group its location is within type L. This difference in the results of traditional classification of ordinary chondrites inspired us to search for alternative method of classification of these meteorites.

In the $4 \mathrm{M}$ method we propose, a classification of ordinary chondrites is based on simultaneous use of 4 parameters obtained from Mössbauer measurements.

Mössbauer spectrum of nonweathered ordinary chondrite consists of four subspectra due to olivine, pyroxene, metallic phase and troilite. These minerals represent more than $95 \%$ of the whole mass of typical ordinary chondrite. In the beginning of XXI century the Mössbauer group of Verma discovered a kind of systematics of the spectra of ordinary chondrites and decided to use Mössbauer spectroscopy for classification of these meteorites. Verma's method is based on a construction of $2 \mathrm{D}$ plots associated with the percentages of spectral areas of the investigated meteorites. This direction of investigation was continued by other groups. A description of these methods, which are only qualitative, was presented by our group [4]. 
Our 4M method is a quantitative one based on multidimensional discriminant analysis, which was implemented to statistics in years 30 of the XX century [5, 6]. Up to now it has been used in many sciences, such as economy, sociology, biology and medicine. The aim of this method is to match the investigated object to a subset of objects creating the basis of specific values of interest. In our case the basis is formed of 3 clusters $\mathrm{H}, \mathrm{L}$ and LL. The clusters are composed of vectors with 4 components: ol, pyr, met and tr. Those components represent percentages of Mössbauer spectral areas associated with olivine, pyroxene, metallic phase and troilite. Using this method one has to choose adequate way to assess the distance of the investigated object to objects forming comparative base. In our model, due to the correlations between percentages of Mössbauer spectral areas, the Euclidean distance is not a correct metrics for determination of distance between the point representing our non-yet classified meteorite and clusters. We proposed therefore, a metrics appropriate for such issues - the Mahalanobis distance [7], which determines the distance between two points in n-dimensional space and differentiates impact of respective variables and takes account the correlations between them.

Mahalanobis distance is dimensionless quantity. Introducing the level of similarity $\mathrm{S}_{\text {cluster }}$ we wanted to present the problem in $1 \mathrm{D}$ dimension space. If we assume that the set of variables is not far from Gaussian distribution, then the level of similarity of investigated meteorite to one of the three clusters can be defined using the probability function $P\left(y \leq \mathrm{d}_{\mathrm{M}} ; \mathrm{s}_{\text {aver }}\right)$. In this function variable $\mathrm{y}$ is smaller or equal to $\mathrm{d}_{\mathrm{M}}$, which is described by the formula:

$$
P\left(y \leq d_{M} ; s_{\text {aver }}\right)=\int_{0}^{d_{M}} \frac{1}{s_{\text {aver }} \cdot \sqrt{2 \pi}} e^{\frac{-y^{2}}{2 s_{\text {aver }}^{2}}} d y
$$

Thus:

$$
S_{\text {cluster }}=\left(1-2 P\left(y \leq d_{M}, s_{\text {aver }}\right)\right) \cdot 100 \%
$$

where: $d_{M}-$ Mahalanobis distance of the investigated meteorite to the centroid of the specific cluster and $\mathrm{s}_{\mathrm{aver}}$ is average variance of the multidimensional cluster.

\section{$24 M$ method - How it works?}

\subsection{Structure of the database for classification of equilibrated ordinary chondrites with the use of $4 \mathrm{M}$ method}

The script prepared by our team for calculation of Mahalanobis distance and level of similarity available at (http://4m-basev1.woreczko.pl/4mmlist.php) was created on the base of 59 Mössbauer spectra of equilibrated ordinary chondrites. 41 of them were obtained in Warsaw laboratory and 18 spectra were taken from literature review. The correctness of the procedure of inclusion to one database the results from different laboratories was confirm in two publications $[8,4]$. Our database is the same as the one published as supplementary data of our paper describing theoretical basis of $4 \mathrm{M}$ method [1]. It consists of 3 clusters: type H (22 meteorites), type L (20 meteorites) and type LL (17 meteorites). Each of the meteorites is represented by a vector with 4 components: ol (the percentage of spectral area of olivine), pyr (the percentage of spectral area of pyroxene), met (the percentage of spectral area of metallic phases), $\mathbf{t r}$ (the percentage of spectral area of troilite). 
Mössbauer studies of the meteorite Pultusk performed at room temperature and at $80 \mathrm{~K}$ [9] and Mössbauer studies of the meteorite Chainpur performed at $289 \mathrm{~K}, 120 \mathrm{~K}, 50 \mathrm{~K}$, $13 \mathrm{~K}$ [10] showed that proportions between percentages of spectral areas associated with olivine, pyroxene, metallic phases and troilite are similar. On the other hand it should be stressed that in the $4 \mathrm{M}$ method this property of the Mössbauer spectra does not play any role.

In next sections the classification with the use of $4 \mathrm{M}$ method of three ordinary chondrites measured and elaborated by our group and the meteorite Villalbeto de la Pena, measured and elaborated in Barcelona [11] will be presented.

\subsection{Mössbauer spectra of $\mathbf{3}$ meteorites: Buzzard Coulee, Mreïra, Mahbas Arraid chosen for classification}

Three samples of meteorites chosen for classification were prepared in standard way: they were crushed and ground into fine powder in an agate mortar under isopropyl alcohol. Then samples were loaded into special absorber holders (diameter $1.4 \mathrm{~cm}$ ). Measurements were performed at room temperature with a conventional Mössbauer spectrometer. The activity of the source ${ }^{57} \mathrm{Co} / \mathrm{Rh}$ was about $3.7 \mathrm{GBq}$.

Determination of the percentages of spectral area associated with 4 main mineral phases present in ordinary chondrites (olivine, pyroxene, Fe-Ni alloy and troilite) was the aim of this study. It is known for the long time that in olivines and pyroxenes iron occupies 2 positions: M1 and M2. To get better quality of fits, the spectra of olivines as well as the spectra pyroxenes were fitted with the use of 2 doublets related to M1 and M2 positions. Fe-Ni alloys are present in ordinary chondrites usually as kamacite, taenite and tetrataenite. Following the nomenclature proposed by Verma they will be named metallic phase (met 1, met 2 and met 3). Iron sulphide in ordinary chondrites type $\mathrm{H}$ and $\mathrm{L}$ is present in form of troilite. In ordinary chondrites type LL beside of real troilite also iron deficient troilite may be present. In such cases the corresponding subspectra were marked as tr1 and tr2.

The spectra were fitted using the Recoil program [12]. All experimental Mössbauer spectra were fitted with Lorentzian lines. The ratio of intensity of lines in sextet was fixed as $3: 2: 1$.

To obtain correct Mössbauer parameters for troilite, the fitting procedure "Full Static Hamiltonian" was applied. As the troilite has an axial symmetry only the theta angle (the angle between direction of the magnetic field and the main axis of the gradient of electric field) was fitted.

Percentage of spectral area of ferric doublet, (the result of weathering) was also determined. The actual version of the $4 \mathrm{M}$ method is constructed for ordinary chondrites with low level of weathering (in which the percentage of spectral area related to $\mathrm{Fe} 3+$ is smaller than $7 \%$ ).

All Mössbauer parameters obtained for meteorites Buzzard Coulee, Mreïra, and Mahbas Arraid are presented in Table 1, and their Mössbauer spectra are shown in Fig. 2.

\subsection{Calculation of Mahalanobis distance and level of similarity for the chosen meteorites}

In Table 2 percentages of spectral areas associated with two sites of olivines $(\mathrm{ol}=\mathrm{ol} 1+\mathrm{ol} 2)$, two sites of pyroxenes $(\mathrm{pyr}=\mathrm{pyr} 1+\mathrm{pyr} 2))$, all metallic phases $($ met $=$ met $1+\operatorname{met} 2+$ met 3$)$ ) and troilite (for Mahbas Arraid $\operatorname{tr}=\operatorname{tr} 1+\operatorname{tr} 2$ ) are shown. 

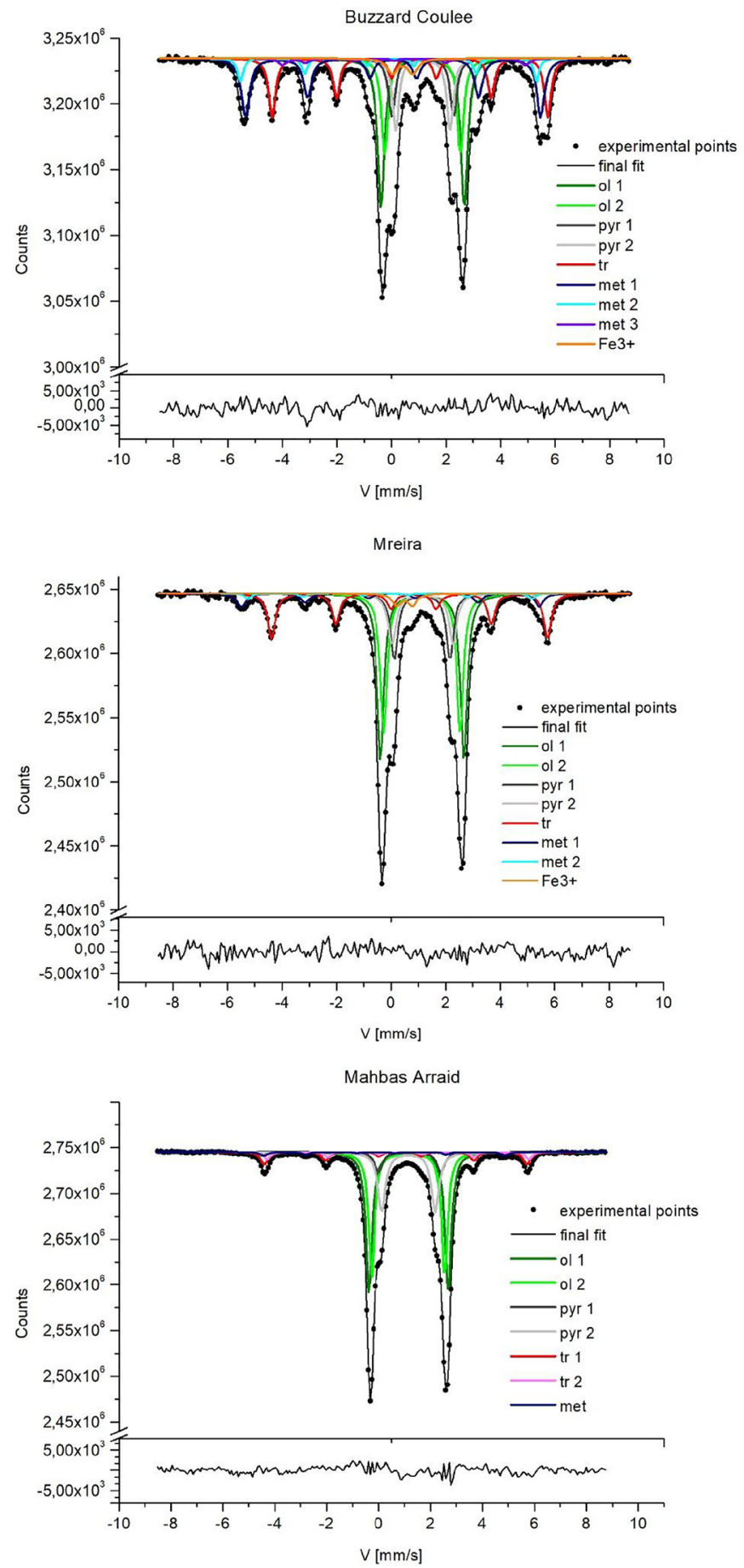

Fig. 2 Mössbauer spectra of meteorites Buzzard Coulee, Mreïra, Mahbas Arraid obtained at room temperature 
Table 1 Mössbauer parameter obtained for meteorites: Buzzard Coulee, Mreïra and Mahbas Arraid

\begin{tabular}{|c|c|c|c|c|c|c|c|c|}
\hline Ordinary chondrite & Mineral phase & $\begin{array}{l}\text { Indication } \\
\text { in Fig. } 2\end{array}$ & $\begin{array}{l}\text { IS } \\
\left(\mathrm{mm} \mathrm{s}^{-1}\right)\end{array}$ & $\begin{array}{l}\mathrm{B} \\
(\mathrm{T})\end{array}$ & $\begin{array}{l}\text { QS } \\
\left(\mathrm{mm} \mathrm{s}^{-1}\right)\end{array}$ & $\begin{array}{l}\Theta \\
\left({ }^{\circ}\right)\end{array}$ & $\begin{array}{l}\mathrm{W} \\
\left(\mathrm{mm} \mathrm{s}^{-1}\right)\end{array}$ & $\begin{array}{l}\text { A } \\
(\%)\end{array}$ \\
\hline Buzzard & olivine (site M1) & ol 1 & 1.15 & - & 3.06 & - & 0.15 & 21.6 \\
\hline Coulee & olivine (site M2) & ol 2 & 1.14 & - & 2.79 & - & 0.14 & 12.8 \\
\hline \multirow[t]{7}{*}{ type $\mathrm{H}$} & pyroxene (site M1) & pyr 1 & 1.14 & - & 2.27 & - & 0.15 & 8.4 \\
\hline & pyroxene (site M2) & pyr 2 & 1.15 & - & 1.98 & - & 0.14 & 9.9 \\
\hline & troilite & $\operatorname{tr}$ & 0.75 & 30.8 & 1.05 & 61.0 & 0.14 & 16.6 \\
\hline & metallic phase 1 & met 1 & 0.06 & 33.6 & 0.00 & - & 0.18 & 19.9 \\
\hline & metallic phase 2 & met 2 & -0.08 & 33.7 & -0.07 & - & 0.12 & 5.3 \\
\hline & metallic phase 3 & met 3 & -0.07 & 27.6 & 1.04 & - & 0.19 & 2.4 \\
\hline & $\mathrm{Fe}^{3+}$ & $\mathrm{Fe}^{3+}$ & 0.40 & - & 0.75 & - & 0.22 & 3.2 \\
\hline Mreïra & olivine (site M1) & ol 1 & 1.15 & - & 3.06 & - & 0.15 & 28.4 \\
\hline \multirow[t]{7}{*}{ type L } & olivine (site M2) & ol 2 & 1.14 & - & 2.80 & - & 0.15 & 23.8 \\
\hline & pyroxene (site M1) & pyr 1 & 1.15 & - & 2.23 & - & 0.17 & 10.1 \\
\hline & pyroxene (site M2) & pyr 2 & 1.14 & - & 2.03 & - & 0.16 & 11.8 \\
\hline & troilite & $\operatorname{tr}$ & 0.75 & 30.9 & 1.02 & 61.2 & 0.16 & 16.7 \\
\hline & metallic phase 1 & met 1 & 0.00 & 33.9 & -0.06 & - & 0.17 & 5.3 \\
\hline & metallic phase 2 & met 2 & -0.12 & 32.3 & 0.16 & - & 0.14 & 1.6 \\
\hline & $\mathrm{Fe}^{3+}$ & $\mathrm{Fe}^{3+}$ & 0.50 & - & 0.56 & - & 0.19 & 2.4 \\
\hline Mahbas & olivine (site M1) & ol 1 & 1.15 & - & 3.05 & - & 0.14 & 34.5 \\
\hline Arraid & olivine (site M2) & ol 2 & 1.14 & - & 2.81 & - & 0.14 & 29.1 \\
\hline \multirow[t]{5}{*}{ type LL } & pyroxene (site M1) & pyr 1 & 1.20 & - & 2.39 & - & 0.18 & 6.1 \\
\hline & pyroxene (site M2) & pyr 2 & 1.15 & - & 2.05 & - & 0.18 & 17.7 \\
\hline & troilite 1 & $\operatorname{tr} 1$ & 0.74 & 30.9 & 0.92 & 62.6 & 0.17 & 6.9 \\
\hline & troilite 2 & $\operatorname{tr} 2$ & 0.80 & 30.7 & 1.02 & 59.5 & 0.14 & 3.6 \\
\hline & metallic phase & met & 0.06 & 28.9 & 0.31 & - & $0.16^{*}$ & 2.1 \\
\hline
\end{tabular}

The obtained percentages of spectral areas for 3 different types of ordinary chondrites $\mathrm{H}$, $\mathrm{L}$ and LL (Table 2) were entered in adequate positions mentioned in the script. The results of calculation of Mahalanobis distances and levels of similarity are given in Table 3 ..

Based on 4M method the highest level of similarity for the Buzzard Coulee meteorite was type $\mathrm{H}$, for the Mreira meteorite - type L, and for Mahbas Arraid - type LL. These results are in agreement with the mineralogical classification based on determination of $\mathrm{Fa} /$ Fs ratio.

\subsection{Classification of the Villalbeto de la Pena meteorite with the use of 4M method}

The fall of the meteorite Villalbeto de la Pena was observed on January 4th 2004 in Spain. In 2007 a paper showing the results of bulk chemistry, porosity, magnetic properties and results of Mössbauer spectroscopy and Raman spectroscopy of this meteorite was published [11] The mineralogical classification (based on measurements with use of electron microprobe) has shown that this meteorite is an ordinary chondrite type L. The authors of cited paper wanted to confirm mineralogical classification by Mössbauer spectroscopy with the use of several plots proposed by Verma group. The results were equivocal. Figure 3 
Table 2 The percentages of Mössbauer spectral areas [\%] associated with olivines (ol), pyroxenes (pyr), metallic phases (met) and troilite (tr) obtained in three ordinary chondrites: Buzzard Coulee, Mreïra, Mahbas Arraid

\begin{tabular}{lllll}
\hline Meteorite & ol & pyr & met & tr \\
\hline Buzzard Coulee & 34.4 & 18.3 & 27.6 & 16.6 \\
Mreïra & 52.2 & 21.9 & 6.9 & 16.7 \\
Mahbas Arraid & 63.6 & 23.8 & 2.1 & 10.5 \\
\hline
\end{tabular}

Table 3 Values of Mahalanobis distance and level of similarity obtained for three ordinary chondrites chosen for classification with the use of $4 \mathrm{M}$ method

\begin{tabular}{llll}
\hline Meteorite & & $\begin{array}{l}\text { Mahalanobis } \\
\text { distance }\end{array}$ & Level of similarity \\
\hline Buzzard Coulee & to type $\mathbf{H}$ & $\mathbf{1 . 8 7}$ & $\mathbf{5 4 . 2 \%}$ \\
& to type $\mathrm{L}$ & 6.37 & $0.8 \%$ \\
& to type $\mathrm{LL}$ & 17.45 & $0.0 \%$ \\
Mreïra & to type H & 3.17 & $30.0 \%$ \\
& to type $\mathbf{L}$ & $\mathbf{0 . 6 2}$ & $\mathbf{7 9 . 3 \%}$ \\
& to type LL & 3.10 & $6.9 \%$ \\
Mahbas Arraid & to type $\mathrm{H}$ & 6.23 & $4.2 \%$ \\
& to type $\mathrm{L}$ & 2.31 & $33.1 \%$ \\
& to type $\mathbf{L L}$ & $\mathbf{1 . 7 6}$ & $\mathbf{4 2 . 4 \%}$ \\
\hline
\end{tabular}
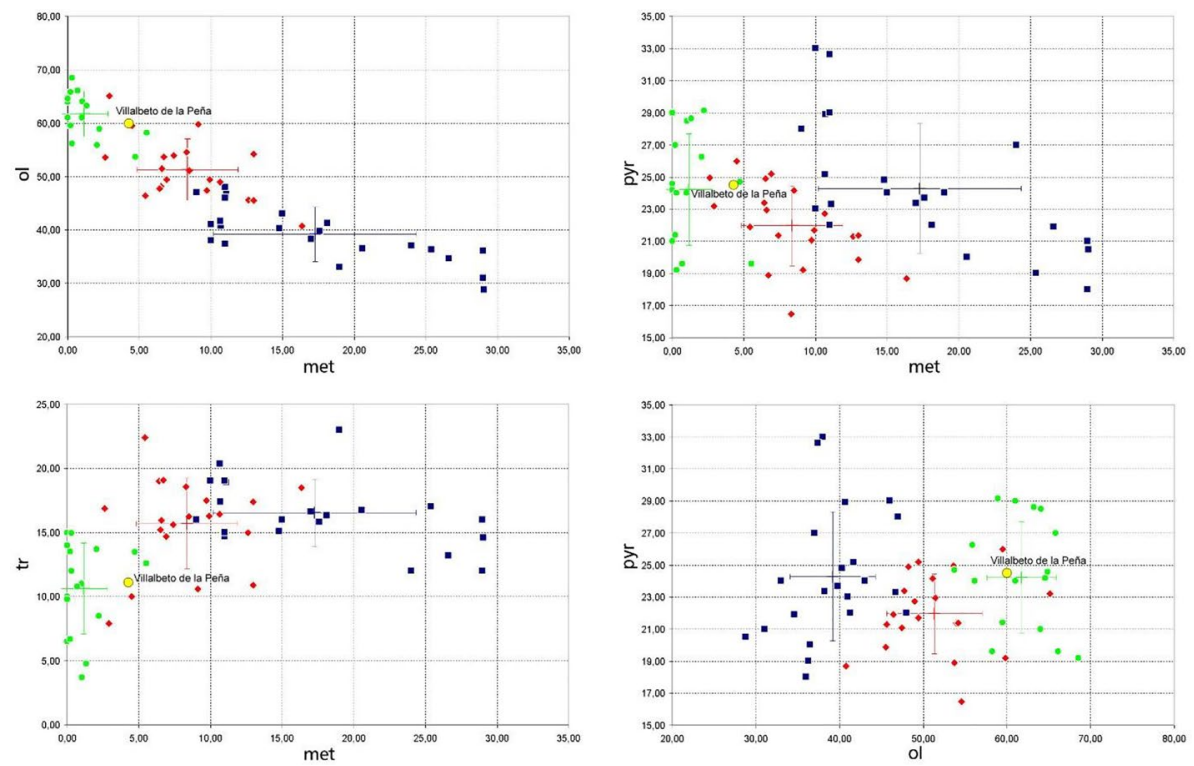

Fig. 3 2D plots type ol vs. met, pyr vs. met, tr vs. met, pyr vs. ol presenting location of the meteorite Villalbeto de la Pena on the background of meteorites from our database 
shows location of the meteorite Villalbeto de la Pena on 2D plots prepared by us with the use of our own database. In all 4 plots meteorite Villalbeto de la Pena is located on the border between LL type and L type meteorites.

Using the percentages of Mössbauer spectral areas published in that paper $(\mathrm{ol}=60.0$, $\operatorname{pyr}=24.6$, met $=4.3, \operatorname{tr}=11.1$ ) we decided to classify this meteorite by $4 \mathrm{M}$ method. Our results (level of similarity to type $\mathrm{H}=8.3 \%$, to type $\mathrm{L}=44.0 \%$, to type $\mathrm{LL}=19.9 \%$ ) confirm the result of traditional classification - the Villalbeto de la Pena meteorite is an ordinary chondrite type $\mathrm{L}$. This example shows that $4 \mathrm{M}$ method is much more effective in classification of nonweathered ordinary chondrites than methods based on 2D plots.

\section{Conclusions}

Our results show that the classification of ordinary chondrites by $4 \mathrm{M}$ method is in agreement with the results obtained with the use of mineralogical method. The experimental part of 4M method is much less time consuming compared to classic one. The mathematical analysis of the results with the use of the presented script is also very simple. This method should be of interest for the Mössbauer society. Although both method $-4 \mathrm{M}$ and classic method - analyze completely different parameters of ordinary chondrites, the results of classification are the same. Analysis of the meteorite Villalbeto de la Pena shows that the strength of $4 \mathrm{M}$ method is based on simultaneous use of 4 parameters related to 4 basic mineral phases present in equilibrated ordinary chondrites. We would like to stress once again - the $4 \mathrm{M}$ method is a quantitative method.

Open Access This article is licensed under a Creative Commons Attribution 4.0 International License, which permits use, sharing, adaptation, distribution and reproduction in any medium or format, as long as you give appropriate credit to the original author(s) and the source, provide a link to the Creative Commons licence, and indicate if changes were made. The images or other third party material in this article are included in the article's Creative Commons licence, unless indicated otherwise in a credit line to the material. If material is not included in the article's Creative Commons licence and your intended use is not permitted by statutory regulation or exceeds the permitted use, you will need to obtain permission directly from the copyright holder. To view a copy of this licence, visit http://creativecommons.org/licenses/by/4.0/.

\section{References}

1. Woźniak, M., Gałązka-Friedman, J., Duda, P., Jakubowska, M., Rzepecka, P., Karwowski, Ł.: Application of Mössbauer spectroscopy, multidimensional discriminant analysis, and Mahalanobis distance for classification of equilibrated ordinary chondrites. Meteorit. Planet. Sci. 54, 1828-1839 (2019). https:// doi.org/10.1111/maps.13314

2. Fredriksson, K., Keil, K.: The iron, magnesium and calcium distribution in coexisting olivine and rhombic pyroxenes in chondrites. J. Geophisic. Res. 69, 3487-3515 (1964)

3. Koblitz, J.: MetBase. Meteorite Data Retrieval Software, Version 7.3 (CD-ROM), Ritterhude, Germany 1994 (2012)

4. Gałązka-Friedman, J., Woźniak, M., Bogusz, P., Jakubowska, M., Karwowski, Ł., Duda, P.: Application of Mössbauer spectroscopy for classification of ordinary chondrites - different database and different methods. Hyperfine Interact. 241, 11 (2020). https://doi.org/10.1007/s10751-019-1661-0

5. Krzanowski, P.: Of Multivariate Analysis: a User's Perspective. Oxford University Press (2000)

6. Morrison, D.F.: Multivariate Statistical Methods. McGraw-Hill, New York (1990) 
7. Mahalanobis, P.C.: On the generalized distance in statistics. Proceedings of the National Institute of Sciences of India. 2, 49-55 (1936)

8. Bogusz, P., Brzózka, K., Górka, B., Szumiata, T., Woźniak, M., Gałązka-Friedman, J.: Classification of meteorites - Mössbauer comparative studies of three ordinary chondrites measured in different conditions. Acta Phys. Pol. A. 134, 1070-1075 (2018). https://doi.org/10.12693/APhysPolA.134.1070

9. Duda, P., Kazulo, P., Setniewski, A., Bogusz, P., Woźniak, M.: Preliminary results of Mössbauer measurements of Pultusk meteorite performed at room temperature $(300 \mathrm{~K})$ and at temperature of liquid nitrogen (80K). Acta Soc. Met. Pol. 9, 48-53 (2018)

10. Elewa, N. N., Cobas, R., Cadogan, J. M.: ${ }^{57}$ Fe Mössbauer study of the chainpur meteorite. Hyperfine Interact 237, 107 (2016) https://doi.org/10.1007/s10751-016-1315-4

11. Llorca, J., Gich, M., Molins, E.: The Villalbeto de la Pena meteorite fall: III. Bulk chemistry, porosity, magnetic properties, ${ }^{57} \mathrm{Fe}$ Mössbauer spectroscopy and Raman spectroscopy. Meteorit. Planet. Sci. 42(suppl), A177-A182 (2007). https://doi.org/10.1111/j.1945-5100.2007.tb00603.x

12. Lagarec K. and Rancourt D. G.: Recoil: Mössbauer Spectral Analysis Software for Windows, Version 1.0. Ottawa: Department of Physics, University of Ottawa. (1998)

Publisher's note Springer Nature remains neutral with regard to jurisdictional claims in published maps and institutional affiliations. 